\title{
A ATUALIDADE E UTILIDADE DA DISSEMINAÇÃO SELETIVA DA INFORMAÇÃO E DA TECNOLOGIA RSS
}

\author{
Murilo Bastos da Cunha ${ }^{\mathrm{i}}$ \\ Thiago Gomes Eirão ${ }^{\text {ii }}$
}

Resumo: $\mathrm{O}$ artigo apresenta os resultados obtidos na pesquisa realizada em bibliotecas de Tribunais em Brasília acerca da atualidade e utilidade da disseminação seletiva da informação (DSI) e da tecnologia RSS. A amostra foi constituída por bibliotecários que trabalhavam no serviço de referência de seis bibliotecas pertencentes a tribunais federais localizados em Brasília. Os resultados obtidos mostram que a DSI é um conceito válido e útil para a disseminação de conteúdos e que a tecnologia RSS ainda é desconhecida e não utilizada por essas bibliotecas.

Palavras-chave: Disseminação seletiva da informação. Serviço de referência. Tecnologia RSS.

\author{
THE TIMELINESS AND USEFULNESS OF SELECTIVE DISSEMINATION OF \\ INFORMATION AND THE RSS TECHNOLOGY
}

\begin{abstract}
This article presents the results obtained in research conducted in libraries of federal courts in Brasilia about the timeliness and usefulness of selective dissemination of information (SDI) and RSS technology. The sample consisted of librarians working in the reference service of six libraries belonging to federal courts located in Brasilia. The results show that the SDI is a valid and useful concept for the dissemination of content and RSS technology is still unknown and not used by such libraries.
\end{abstract}

Keywords: Selective dissemination of information. Reference service. RSS technology.

\footnotetext{
${ }^{\mathrm{i}}$ Universidade de Brasília. murilobc@unb.br.

ii Centro de Documentação da Câmara dos Deputados. thiagoe@gmail.com.

Recebido em: 04/12/2011; aceito para publicação em: 20/12/2011.
} 


\section{INTRODUÇÃO}

Já há tempo o homem vem reunindo livros, pergaminhos e rolos de papel pensando na preservação da memória e do conhecimento produzido. Seja em pequenas bibliotecas pessoais ou em grandes bibliotecas, como a de Alexandria, a organização de tais itens tinha como meta facilitar o acesso às informações armazenadas em diversos formatos.

Segundo Manguel (2006, p. 33), até a fundação da biblioteca de Alexandria, as bibliotecas do mundo antigo eram coleções particulares das leituras de determinado homem ou depósitos governamentais em que se preservavam documentos legais e literários para consulta oficial. A Biblioteca de Alexandria foi criada para fazer outras coisas, além de imortalizar, ela deveria registrar tudo o que já existira e pudesse ser registrado, e esses novos itens deveriam gerar novos registros, numa sequência infinita de leituras e comentários que por sua vez engendrariam novos comentários e novas leituras. Essa biblioteca foi fundada no final do século III a. C. e contava com um acervo de aproximadamente 600 mil rolos de pergaminhos.

Talvez nessa época, a guarda de todo o conhecimento do mundo fosse algo fácil, já que a produção de conhecimento era restrita a poucos intelectuais e pensadores. A organização poderia ser feita rapidamente por bibliotecários como uma tarefa normal de trabalho. Entretanto, em pleno século XXI, pensar nessa tarefa é, no mínimo, uma missão audaciosa para qualquer biblioteca. Nem mesmo o maior acervo do mundo, hospedado pela Biblioteca do Congresso dos Estados Unidos (Library of Congress), com seus 145 milhões de itens, em 470 línguas diferentes e o projeto da biblioteca digital mundial, tem conseguido acompanhar a rápida expansão das publicações.

O surgimento da chamada Sociedade da Informação, dentre outros fatores, ocasionou o crescimento da produção intelectual e de publicações. Segundo Sardenberg (2000, p. 5), esta é, em escala mundial, uma sociedade fundamentada em novas formas de organização e de produção de informações. De acordo com Takahashi (2000, p. 3) a sociedade da informação surge da convergência entre conteúdos, computação e comunicação. Esta junção criou um aumento exponencial de publicações e informações produzidas.

Para se ter uma ideia, Kuramoto (2008, p. 155), estimou que, em todo o mundo, um milhão de artigos técnicos e científicos é produzido anualmente. Imaginar uma biblioteca capaz de guardar todo esse conhecimento e disseminá-lo para seu público é algo quase impossível, mesmo com a existência das tecnologias e das publicações online. 
Portanto, são múltiplos os desafios de um mundo globalizado, sendo até mesmo difícil obter consenso sobre quais seriam os prioritários. Todavia, um deles - tornar o conhecimento acessível a todos - destaca-se como o mais importante devido aos seus efeitos estruturantes. "Em nenhuma época da história, a produção de conhecimentos foi tão intensa como nos dias de hoje, como também em nenhuma outra época a sua aplicação assumiu papel tão preponderante". (DEFOURNY, 2006, p. 7)

Cientes dessa realidade, as bibliotecas e a própria Ciência da Informação têm trabalhado ao longo dos anos, no desenvolvimento do tratamento, organização e uso da informação e do conhecimento. Para Tarapanoff (2006, p. 19), a Ciência da Informação é:

[...] uma ciência de caráter eminentemente interdisciplinar, que tem por objeto o estudo das propriedades gerais da informação (natureza, gênero e efeitos). Assim, em pesquisas que abordam o tema da informação, a ciência da informação contribui principalmente com estudos das necessidades informacionais, do estudo do fluxo e uso da informação.

Centrada na melhoria do fluxo informacional, a Ciência da informação vem contribuindo para que as organizações que lidam com recursos informacionais, especificamente bibliotecas, possam se adequar aos novos desafios que o mundo globalizado impõe. Hjörland (2003, p. 88), afirmou que a Ciência da Informação busca a melhor utilização do conhecimento presente em diversos itens e que as bibliotecas devem ter como objetivo fornecer acesso físico e intelectual à informação.

Aproveitando-se do desenvolvimento da tecnologia informacional, somando-se a isso a necessidade de expandir serviços e produtos, as bibliotecas entraram na era eletrônica com os sistemas de gerenciamento de bibliotecas, catálogos públicos de acesso em linha e sistemas informacionais mais complexos. Vale aqui ressaltar que sistemas de informação não são apenas aqueles que utilizam o computador, mas também aqueles que organizam e estruturam a informação. Para Harter (apud SOUTO, 2008, p. 2), os catálogos em fichas de uma biblioteca podem ser considerados um sistema de informação.

A partir do aumento significativo da produção científica aumenta-se a necessidade de registrar a informação, reuni-la e organizá-la. Assim, concebeu-se a ideia do que viriam a ser sistemas de recuperação de informações. (SOUTO, 2008, p. 2).

Rowley (2002, p. 5) define os sistemas de informação como aplicativos de recuperação que dão acesso a informações, especialmente àquelas em formato eletrônico. $\mathrm{O}$ advento desses sistemas e da Internet foram fatos determinantes para a melhoria nos serviços prestados por bibliotecas aos seus usuários. Porém, com o passar do tempo e o crescimento desorganizado da Internet, Lancaster (2004, p. 339) observou que ao invés de ser uma 
ferramenta de auxílio, a Internet transformou-se em um ponto de problema, já que segundo o autor, os recursos de busca e organização dos dados são "[...] rudimentares comparados com o uso de uma base de dados cuidadosamente indexada" (LANCASTER, 2004, p. 343).

Daí surge o papel do profissional da informação, dentre eles o bibliotecário, com a missão de facilitar e fazer a conexão entre a informação e o usuário que deseja obtê-la. Fröehlich (1989, p. 308), afirma que os profissionais da informação são os agentes educadores e facilitadores do processo de acesso e disseminação da informação. Diante desta função, os bibliotecários têm atuado no processamento e organização das informações em classes de assuntos. Porém, essa organização já não se mostra tão eficiente de acordo com a necessidade dos usuários, pois

[...] à medida que o volume dos documentos a processar e a ordenar aumenta além de certo ponto crítico, não é mais possível contentar-se com a organização dos documentos por grandes classes, pois o usuário exige informações muito mais precisas na representação do conteúdo dos documentos, para poder chegar o mais rapidamente possível àqueles, e só àqueles que lhe interessam. (ROBREDO, 2006, p. 312).

O usuário, cada vez mais, passou a exigir especificidade e seletividade no pacote informacional recebido. Fonseca (1988, p. 29), relatou uma série de ações que o bibliotecário deve fazer para desempenhar sua função, uma delas era “[...] ser bibliotecário para selecionar os livros e as revistas pensando nas necessidades dos leitores".

Segundo Dias e Pires (2004, p. 5), conhecer o comportamento do usuário de informação é importante tanto para o planejamento como para o desenvolvimento e prestação do serviço de informação, para que o mesmo possa atender de forma precisa o consumidor da informação. De acordo com Wilson (2000, p. 3), os usuários de informação estão mais exigentes, já que seu comportamento informacional e necessidades de informação são influenciados por diversos fatores além da perspectiva organizacional, por isso cabe à biblioteca conhecer e tentar antecipar os desejos de seu usuário.

Para Carvalho (2008, p. 123), uma forma de conhecer tal necessidade é a educação do usuário de acordo com o mapeamento de suas competências. Já na antecipação das necessidades não são necessárias grandes invenções para satisfazer os usuários, já existem instrumentos à disposição para isso. A Internet, por exemplo, pode ser entendida como uma dessas ferramentas de apoio ao desenvolvimento de novos produtos informacionais, já que

[...] representa uma mudança de paradigma radical com relação aos serviços bibliotecários. Ela proporciona um ambiente informacional amplo, global, de alcance nunca visto pelos antigos serviços bibliotecários, acostumados a trabalhar num ambiente delimitado, com uma comunidade de usuários identificável, restrita e até mesmo, conhecida pessoalmente. No novo ambiente, numa escala mundial, os 
usuários podem ter acesso a diferentes recursos, independentes de sua localização física (MARCONDES; MENDONÇA; CARVALHO, 2006, p. 175).

Um dos instrumentos que se apresentam para o profissional da informação é o próprio serviço de disseminação seletiva da informação (DSI) $)^{3}$ e a tecnologia Rich Site Summary (RSS), serviços que podem gerar bons resultados à instituição. O RSS é um conjunto de especificações voltadas para a agregação e distribuição de conteúdos da web, que facilita o processo de consulta e partilha de informação proveniente de diversas fontes de informação, periodicamente sujeitas a alterações ou atualizações, gerando uma economia de tempo com a leitura de informações de diversos sítios em um único ambiente e a possibilidade de agregar somente aquelas informações que pertencem à área de interesse da pessoa.

\section{DISSEMINAÇÃO SELETIVA DA INFORMAÇÃO}

A Disseminação Seletiva de Informação ou apenas DSI, é a tradução do termo inglês selective dissemination of information (SDI). Aparentemente três palavras de simples entendimento que podem produzir um grande problema ou solução. Duas das clássicas Leis de Ranganathan (1963) ("Poupe o tempo do usuário" e "Para cada leitor seu livro") ajudam a entender a Disseminação Seletiva da Informação, que pode ser um serviço personalizado, de valor agregado e direcionado para a necessidade particular de cada usuário.

\section{Segundo Reitz ${ }^{4}$ (2004), DSI é}

um serviço ou uma publicação destinada a alertar os estudiosos, pesquisadores, leitores, clientes ou empregados para a literatura publicada recentemente em seu campo (s) de especialização, geralmente disponíveis em bibliotecas especializadas, servindo as empresas, organizações e instituições em que o acesso a informações atualizadas é essencial.

Já Cunha e Cavalcanti (2008, p. 130), definem a DSI como “difusão automática, selecionada, permanente e personalizada de informações correntes, relativas a assuntos específicos [...] notificação seletiva”. Essa notificação pode ser chamada também, em inglês, de current awareness, termo que tem seu estudo muito próximo dos conceitos da DSI.

Segundo Lima et al. (2001), a DSI não é algo precisamente novo. Ela desenvolveu-se, de forma mais sistematizada, a partir das décadas de 1950/1960, a partir dos estudos de Hans

\footnotetext{
${ }^{3}$ Termo proveniente do inglês Selective Dissemination of Information (SDI). Para fins de padronização usa-se o termo e a sigla em português.

4 Dicionário online para Biblioteconomia e Ciência da Informação. Disponível em: $<$ http://lu.com/odlis/odlis_c.cfm\#currentawareness>. Acesso em: 22 jan. 2011.
} 
Peter Luhn, da IBM Corporation, com o objetivo de minimizar esforços dos cientistas na busca de informações relevantes para o trabalho de pesquisa. A sua aceitação foi rápida já que se configurava por ser um serviço personalizado oferecido diretamente ao usuário de acordo com seu perfil e linha de pesquisa, permitindo ao centro de informação a possibilidade da criação de uma conexão direta e mais rápida com os interesses de cada usuário.

Luhn (1958), imaginou o desenvolvimento de um sistema automático de disseminação de informação de vários setores da área científica e de organizações governamentais. Esse sistema se utilizaria de dados compilados por equipamentos eletrônicos para a construção dos perfis de interesse.

Hensley (1963, p. 1), confirma a rápida expansão das ideias de Luhn e chama o conceito criado por ele como selective dissemination of information (DSI, em português). De acordo com Hensley (1963), esse serviço foi utilizado pela primeira vez em 1959, pela IBM em Yorktown Heights, New York. O serviço consistia no funcionamento conjunto de um sistema de processamento de dados, máquinas de cartões perfurados, máquinas de cópia e pessoas. O serviço processava uma pequena quantidade de documentos e comparava com os perfis de interesse de trinta usuários.

Em 1960 foi testado um segundo serviço de DSI, a partir dessa experiência pioneira. A diferença é que a segunda DSI foi um sistema totalmente planejado e documentado, permitindo sua divulgação. Em 1961 a documentação da segunda DSI estava completa e foi feito o primeiro anúncio público do serviço.

Luhn (1961, p. 132), definiu a DSI como

[...] aquele serviço dentro de uma organização que se refere à canalização de novos itens de informação, vindos de quaisquer fontes, para aqueles pontos onde a probabilidade de utilização, em conexão com o interesse corrente do usuário, seja alta.

Após os primeiros trabalhos de Luhn, os conhecimentos em torno do desenvolvimento da DSI passaram a ser utilizados em diversas áreas do conhecimento, em especial na química, biologia, informática, física e medicina. Na área de biologia inclusive já se discutiam formas de oferecer esse serviço de maneira computadorizada.

No Brasil os primeiros estudos sobre a DSI surgem na década de 1970, ligados principalmente aos centros de informação de órgãos públicos. Raulino (1973), propôs a constituição de um sistema de indexação, armazenagem e recuperação de informações que propiciaria a construção de um sistema de disseminação seletiva de informação da produção do Congresso Nacional. No mesmo ano, Borda (1973), elaborou um artigo de revisão de literatura comentando sete artigos publicados entre 1958 e 1971. Além disso, o autor 
comentou as características fundamentais dos sistemas de disseminação seletiva da informação e apresenta a proposta de DSI para a Companhia Vale do Rio Doce.

A partir disso, no Brasil começam a aparecer relatos de experiências na utilização da DSI. Ferraz e Figueiredo (1978), apresentaram o serviço de DSI do Instituto de Energia Atômica de São Paulo; / relatou os resultados obtidos no serviço de SDI da Embrapa; Chastinet et al. (1978) relataram o serviço de disseminação seletiva na área de agricultura. Mas 1978 foi realmente um ano de grande expansão do tema no Brasil, levando a Revista de Biblioteconomia de Brasília ${ }^{5}$ a lançar uma edição dedicada a discutir a DSI no contexto brasileiro.

Na realidade brasileira, inicialmente a prestação do serviço de disseminação seletiva de informação era feita por bibliotecas especializadas. Esse serviço era elaborado manualmente com base no acervo local de periódicos, para a produção de listas selecionadas de títulos e artigos e a distribuição de resumos a poucos usuários. Segundo Almeida (2008, p. 36), com o surgimento de novas tecnologias o serviço de DSI foi gradativamente incorporado aos formatos eletrônicos e aos sistemas informatizados. Dessa forma, as pesquisas bibliográficas ganharam agilidade.

Para Bax et al. (2004), um típico serviço de DSI tem por objetivo prover cada usuário inscrito uma lista periódica e personalizada, dos novos trabalhos que deram entrada na base de dados e que podem se constituir em subsídios para trabalhos em andamento ou interesses. Assim, cada usuário inscrito recebe um diferente conjunto de informações referenciais, dependendo de seus interesses particulares, tal como definido previamente, em seu respectivo "perfil de interesse". Segundo esse autor é cada vez mais comum a ideia do surgimento de um sistema de disseminação de informação automático.

Nos últimos anos a DSI torna-se, com o aumento da demanda de informação e com crescimento da tecnologia, um importante instrumento de suporte para as organizações que desejam difundir informações de maneira prática e ágil. Segundo Lucas e Souza (2007, p. 2), a grande quantidade de informações produzidas, aliadas ao desenvolvimento de conhecimentos novos, criou uma exigência de "metodologias específicas que permitam a escolha, busca e recuperação do conhecimento personalizado". Ainda segundo as autoras, o serviço eletrônico de DSI tornou os usuários da biblioteca mais próximos dela, já que "[...] passam efetivamente a utilizar seus serviços de maneira personalizada".

\footnotetext{
${ }^{5}$ Revista de Biblioteconomia de Brasília, v. 6, n. 2, 1978.
} 
O trunfo da DSI reside no poder conferido ao usuário em decidir o que deseja ou não receber. "A prática da gestão do conhecimento, requer que a organização crie mecanismos eficazes que proporcionem tanto a produção dinâmica e contínua do conhecimento, como o seu registro e o compartilhamento" (LIMA et al., 2001, p. 195). Dessa forma, a proposta de implantação de um serviço de DSI, como um mecanismo de compartilhamento de informações, redireciona o foco da oferta para o foco da demanda dos usuários, em função dos objetivos da organização e se mantém atual com as novas tecnologias existentes.

Segundo Cunha (1999), com a biblioteca digital “a DSI não ficará restrita aos documentos tradicionais, notadamente a livros e artigos científicos; poderá incluir, ainda, noticiário em linha das agências de notícias, jornais, rádio e televisão, mercado das bolsas de valores, programação cinematográfica".

\section{TECNOLOGIA RSS}

Em 1997, com a expansão da Internet, surge próxima ao conceito de disseminação seletiva de informação (DSI), a tecnologia RSS - (Rich Site Summary, Really Simple Syndication ou ainda conhecida como RDF Site Summary) com a finalidade de permitir notificar automaticamente os usuários sobre novos conteúdos na web, por meio do arquivotexto codificado conhecido como feed. Os feeds são segundo Almeida (2008, p. 90), “[...] lista constituída pelos elementos essenciais que descrevem uma determinada informação da Web: o título do documento, o seu URL (Uniform Resource Locator), o endereço que localiza os sítios na web e uma breve descrição de seu conteúdo".

Os feeds estão organizados em uma linguagem estruturada, onde todos os elementos são categorizados através de $\operatorname{tags}^{6}$ específicas, tais como <author $>$, <title $>$, etc. Essa estruturação permite aos navegadores interpretarem e apresentarem o conteúdo de maneira correta. Além disso, a categorização dos conteúdos permite uma melhor recuperação das informações do sítio, já que os mecanismos ou motores de busca irão registrar os elementos encontrados com sua definição. Por questões de visualização, o conteúdo não é apresentado desta forma ao usuário.

O RSS utiliza a linguagem XML (Extensible Markup Language), linguagem de marcação e descrição de dados em páginas web, com a finalidade de organização maior dos

\footnotetext{
${ }^{6}$ Rótulos usados para informar ao navegador como deve ser apresentado o conteúdo do website
} 
conteúdos eletrônicos. Segundo Alecrim (2005), a primeira versão do RSS foi criada pela Netscape para o seu portal My Netscape e se chamava RSS 0.90. Sem ver viabilidade do projeto, a Netscape abandona o produto. Tempos depois a Userland, empresa de menor porte, resolve continuar o RSS para utilizá-lo em seu blog. Em 2003, foi lançada a versão RSS 2.0, sob a responsabilidade da RSS Advisory Board ${ }^{7}$, entidade responsável por manter e atualizar essa tecnologia. A última atualização é de 2007, quando foi lançada a versão 2.0.10. A Figura 1 mostra o símbolo criado para a tecnologia RSS.

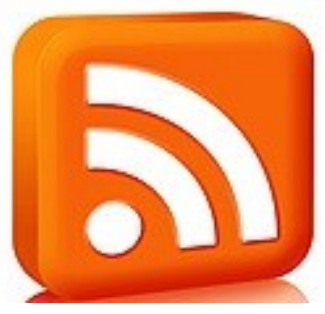

Figura 1: símbolo da tecnologia RSS

O RSS foi criado para simplificar o tráfego das informações dos sítios através da web. Ele é a comunicação dos novos conteúdos disponibilizados na Internet, desejados por uma pessoa para o seu computador pessoal. Segundo Rocha e Bezerra (2010, p. 91)

[...] o RSS é um formato estrutural que auxilia os usuários a agregarem informações de muitas origens diferentes na web, proporcionando a divulgação de publicações provenientes da Internet. Qualquer dado na Internet pode se tornar um feed RSS, por exemplo, uma notícia de jornal, um artigo científico etc. Algumas vantagens do uso do RSS são: a informação mais atual de um feed RSS está sempre disponível; ele permite que as informações sejam capturadas por programas leitores; seus assinantes não precisam usar sua caixa de e-mail para acessar as informações; ele é gratuito; e trata-se de um protocolo de conteúdo estruturado e reusável.

Nesse contexto existe uma mudança do paradigma: ao invés da pessoa procurar pela informação, é a informação que segue o indivíduo. O funcionamento dessa tecnologia é relativamente simples, basta o usuário possuir um leitor do conteúdo RSS, também conhecido como agregador de conteúdo, dos feeds e nesse leitor selecionar suas áreas de interesse. Singh (2008) mostrou as diversas formas que uma pessoa pode utilizar essa tecnologia, que inclusive já está disponível nos smartphones ${ }^{8}$. A Figura 2 mostra como o usuário se informa sobre vários assuntos sem a utilização da tecnologia RSS e a Figura 3 mostra como o usuário se informa com o uso da tecnologia RSS.

\footnotetext{
${ }^{7}$ Disponível em: http://www.rssboard.org/. Acesso em 22 dez. 2010.

${ }^{8}$ Celulares que possuem funções e programas de computador. Podem ser entendidos como computadores de bolso;
} 


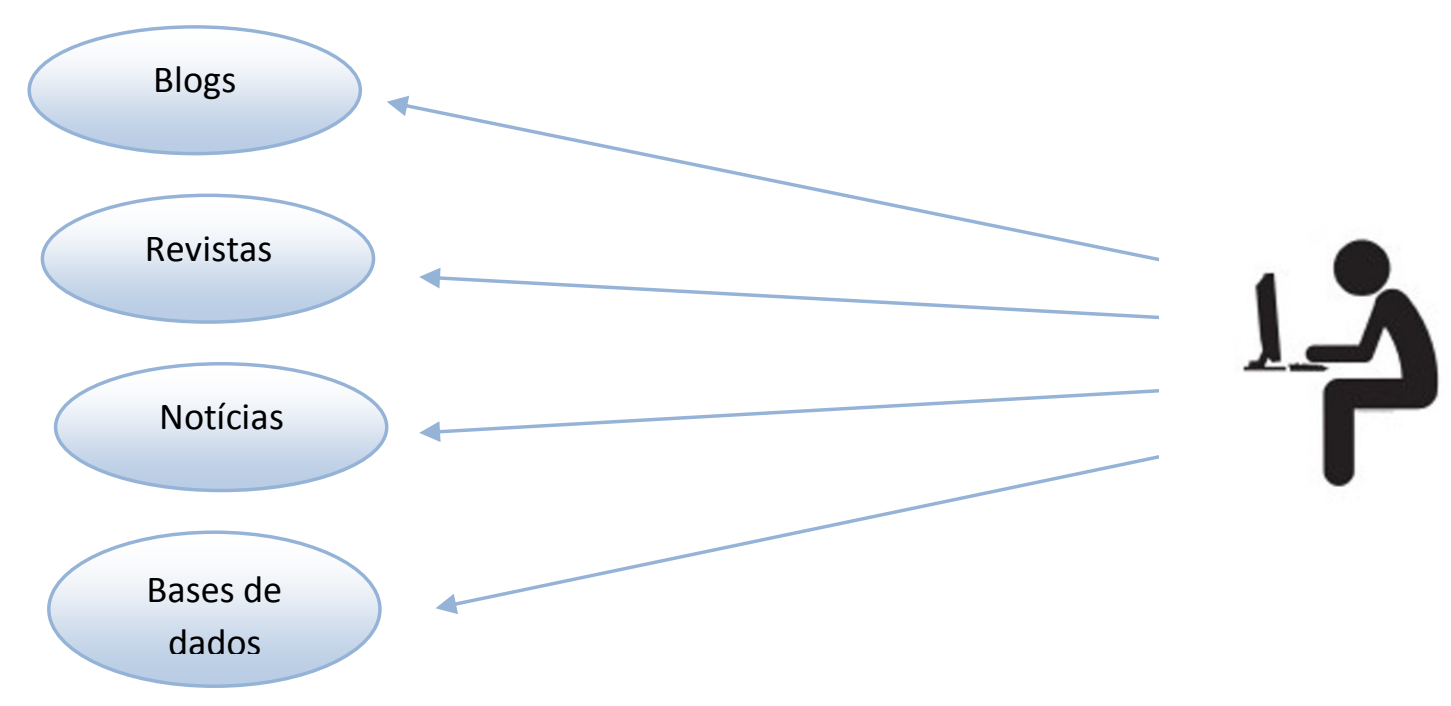

Figura 2: Como o usuário se informa sem utilizar a tecnologia RSS

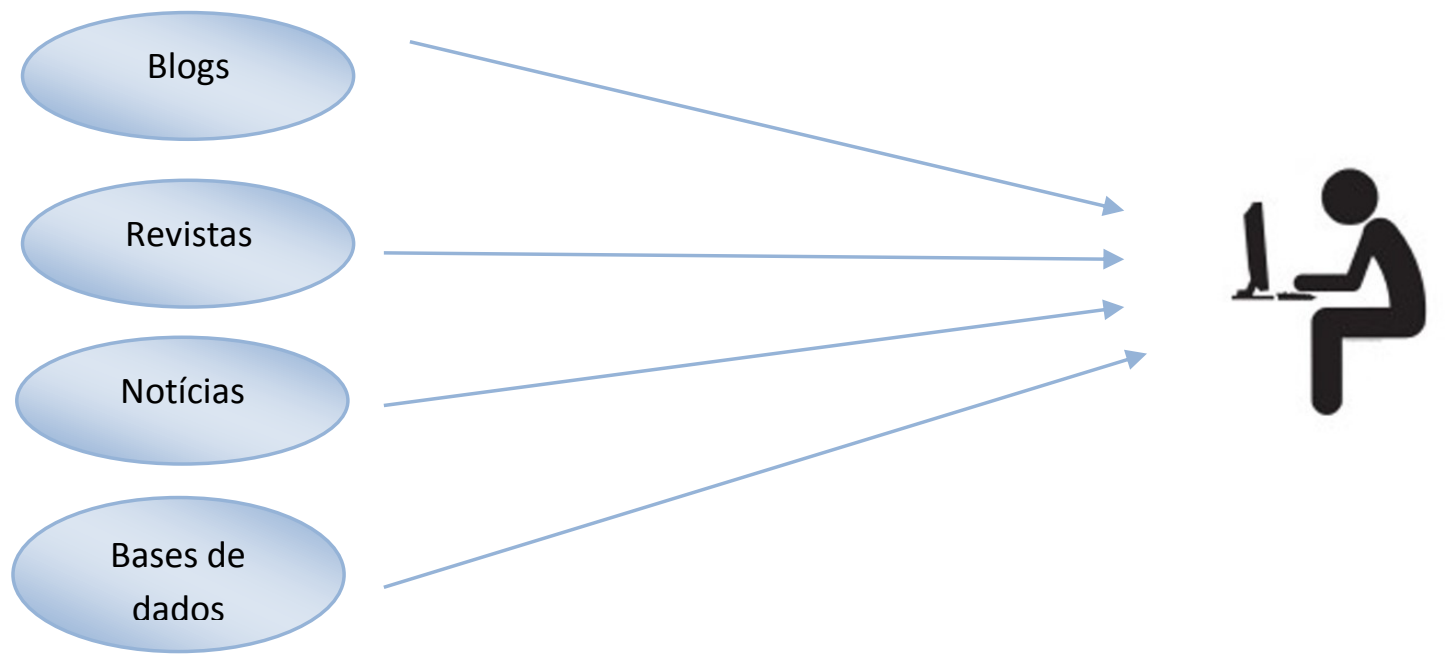

Figura 3: Como o usuário se informa utilizando a tecnologia RSS

Levine (2003) definiu essa tecnologia como uma maneira rápida de obtenção de informação, por meio da escolha de fontes específicas de informação da Internet, sendo uma forma eficiente de revisão das últimas informações publicadas nas várias páginas web. Após a seleção, o indivíduo, receberá apenas aquelas informações ou atualizações de informações, referentes somente à área selecionada previamente no leitor.

MacManus (2009) observou de forma arguta que o mercado dos leitores de RSS apresenta declínio, embora a utilização da tecnologia em si, continue a crescer. Segundo esse autor tal declínio é explicado pelo domínio do mercado de leitores pelo Google, o crescimento 
de experiências como Twitter $^{9}$ e Facebook $^{10}$ e os próprios navegadores já possuírem seu próprio leitor dos feeds.

O RSS é um conjunto de especificações voltadas para a agregação e distribuição de conteúdos da web, que facilita o processo de consulta e partilha de informação proveniente de diversas fontes de informação, periodicamente sujeitas a alterações ou atualizações. Isso gera uma economia de tempo com a leitura de informações de diversos sítios em um único ambiente e a possibilidade de agregar somente aquelas informações que pertencem à área de interesse da pessoa. Badman e Hartman (2008, p. 670) incluíram o RSS como solução para a disseminação dos conteúdos dos periódicos científicos que cada vez mais se apresentam apenas na forma eletrônica.

Com a popularização dessa tecnologia, as bibliotecas e centros de informação começam a reconhecer nessa ferramenta uma oportunidade de inovação no serviço de referência. Wusteman (2004, p. 404) apontou que embora a área de atuação do RSS ainda seja recente, as bibliotecas têm identificado nessa tecnologia ferramentas úteis para um número crescente de tarefas. Anderson (2006, p. 115) assinala os feeds como o futuro da comunicação de textos eletrônicos, além de serem ferramentas capazes de auxiliar os serviços de referência a responder questões relacionadas aos documentos eletrônicos.

\section{METODOLOGIA}

O presente estudo se realizou por meio de uma pesquisa descritiva qualitativa, com objetivo geral de verificar a aplicabilidade da tecnologia RSS e da DSI nos serviços de referência das bibliotecas de Tribunais em Brasília. O universo de pesquisa foi delimitado em seis órgãos do Poder Judiciário: Supremo Tribunal Federal (STF); Superior Tribunal de Justiça (STJ); Superior Tribunal Militar (STM); Tribunal Superior Eleitoral (TSE); Tribunal Superior do Trabalho (TST) e o Tribunal de Justiça do Distrito Federal e Territórios (TJDFT).

Constituíram-se como a população da pesquisa os bibliotecários que atuam no serviço de referência e atendimento ao usuário de cada órgão. Por questões de viabilidade da pesquisa, foi elaborado um plano de amostragem não-probabilística. A amostra foi composta pela pessoa mais antiga e mais nova no serviço. Essa seleção teve por finalidade identificar as

\footnotetext{
${ }^{9}$ Rede social em formato de microblog que permite aos usuários enviarem e receberem atualizações, de no máximo 140 caracteres, suas e das demais pessoais que estão em conexão com o seu perfil.

${ }^{10}$ Rede social que permite a conexão entre pessoas e o compartilhamento de imagens, vídeos e aplicativos.
} 
diferentes percepções sobre o próprio serviço de referência e principalmente as diferenças existentes no conhecimento de novas tecnologias na área da informação, devido ao espaço temporal de formação dos profissionais.

A técnica utilizada para o desenvolvimento dessa pesquisa foi a entrevista semi-aberta. Cervo, Bervian e Silva (2007, p. 51) entendem a entrevista como "uma conversa orientada para um objetivo definido: recolher, por meio do interrogatório do informante, dados para a pesquisa". A entrevista é uma técnica que permite ao pesquisador obter informações que não podem ser encontradas em documentos ou outras técnicas de coleta de dados. Por ser uma "conversa" a entrevista permite o aprofundamento das variáveis durante a realização da mesma. Para a organização das questões foi elaborado um roteiro contendo 18 questionamentos norteadores da entrevista. As entrevistas foram realizadas em setembro de 2010. O Quadro1 mostra a relação entre as perguntas e os objetivos específicos da pesquisa.

\begin{tabular}{|c|c|c|c|c|c|}
\hline $\begin{array}{l}\text { Objetivos } \\
\text { específicos }\end{array}$ & $\begin{array}{c}\text { Caracterizar as } \\
\text { bibliotecas de } \\
\text { Tribunais em } \\
\text { Brasília }\end{array}$ & $\begin{array}{l}\text { Verificar como é } \\
\text { realizado o serviço } \\
\text { de referência das } \\
\text { bibliotecas de } \\
\text { direito em Brasília }\end{array}$ & $\begin{array}{c}\text { Verificar o } \\
\text { conhecimento dos } \\
\text { profissionais sobre } \\
\text { a tecnologia RSS }\end{array}$ & $\begin{array}{c}\text { Identificar os } \\
\text { recursos tecnológicos } \\
\text { utilizados no serviço } \\
\text { de referência }\end{array}$ & $\begin{array}{c}\text { Verificar a opinião } \\
\text { dos bibliotecários do } \\
\text { serviço de referência } \\
\text { a relevância do } \\
\text { serviço de DSI }\end{array}$ \\
\hline Pergunta 1 & $x$ & & & & \\
\hline Pergunta 2 & & $x$ & & & \\
\hline Pergunta 3 & & $x$ & & & \\
\hline Pergunta 4 & & $x$ & & & \\
\hline Pergunta 5 & & $x$ & & & \\
\hline Pergunta 6 & & $x$ & & & \\
\hline Pergunta 7 & & $x$ & & & \\
\hline Pergunta 8 & & $x$ & & & \\
\hline Pergunta 9 & & & $x$ & & \\
\hline Pergunta 10 & & & $x$ & & \\
\hline Pergunta 11 & & & $x$ & & \\
\hline Pergunta 12 & & & & $x$ & \\
\hline Pergunta 13 & & & & $x$ & \\
\hline Pergunta 14 & & & & $x$ & \\
\hline Pergunta 15 & & & & & $x$ \\
\hline Pergunta 16 & & & & & $x$ \\
\hline Pergunta 17 & & & & & $x$ \\
\hline Pergunta 18 & & & & & $x$ \\
\hline
\end{tabular}

Quadro 1: Relação entre as perguntas e os objetivos específicos da pesquisa 


\section{RESULTADOS}

Ao todo foram visitadas seis instituições totalizando onze entrevistados. De acordo com a metodologia, seriam dois entrevistados em cada órgão, porém o Superior Tribunal Militar (STM) possuía apenas uma pessoa trabalhando no serviço de referência, acumulando todas as funções do serviço. Todos os entrevistados eram do sexo feminino.

A média de tempo de formatura dos profissionais entrevistados foi de 11 anos. A pessoa mais antiga formou-se em 1978 e a mais recente, em 2007. A média do tempo no serviço de referência é aproximadamente de sete anos, sendo que a pessoa mais recente estava apenas há dois meses no setor e a mais antiga, vinte e cinco anos.

Dos onze entrevistados, seis afirmaram não conhecer a tecnologia RSS ou não souberam explicar o que ela era. Após a apresentação de uma explicação genérica dessa tecnologia, os entrevistados afirmaram entender superficialmente o que ela viria a ser. Vale ressaltar que, os entrevistados que leram a explicação, ao verem o símbolo da tecnologia afirmaram já ter visto em algum site ou em seu próprio navegador. Apenas um entrevistado não reconheceu o símbolo.

É interessante observar que muitos conheciam o símbolo, no entanto, não sabiam ou não tiveram curiosidade de conhecer o que ele representava e a tecnologia. Talvez esse fenômeno possa ser explicado pelo baixo uso do sítio das bibliotecas entrevistadas e de outras ferramentas de redes sociais ${ }^{11}$, já que a utilização dessa tecnologia necessariamente está ligada a sítios, blogs e demais espaços no mundo digital. Dos seis entrevistados que não conheciam a tecnologia, cinco pertenciam ao grupo de pessoas que está há mais tempo formado, apenas um entrevistado, que não conhecia a tecnologia pertencia ao grupo que tinha menos tempo de formatura

Dos onze entrevistados, oito responderam que vêem utilidade dessa tecnologia no serviço de referência. Três entrevistados que disseram não conhecer a tecnologia, após lerem a explicação, disseram enxergar utilidade da tecnologia. Apenas três entrevistados disseram não ser uma tecnologia útil em bibliotecas.

Ao serem questionados onde poderia ser aplicada essa tecnologia, a resposta mais comum foi a utilizada para divulgação rápida e ampla de informações breves sobre a biblioteca, sem a necessidade de a mesma entrar em contato individualmente com cada

${ }^{11}$ Twitter, Facebook, Youtube são exemplos de redes sociais que utilizam tecnologia RSS. 
usuário. Outra resposta comum foi a possibilidade do serviço de referência poder se atualizar sobre vários sítios sem a necessidade de visitá-los individualmente.

Segundo dois entrevistados, essa tecnologia não seria útil, já que o sítio da biblioteca não é muito desenvolvido. Um entrevistado respondeu que este tipo de "novidade" é válido, apenas para bibliotecas universitárias, já que são elas que realmente lidam com pesquisas sobre itens mais recentes. Indagados se os serviços de referência já tiveram alguma iniciativa em utilizar a tecnologia RSS, todos responderam que essa tecnologia nunca foi cogitada para ser implantada no serviço. Nenhum outro profissional pensou em utilizá-la nem houve qualquer discussão acerca disso entre os entrevistados e demais colegas de serviço.

Já sobre a DSI, todos os usuários responderam que conheciam e explicaram o que seria, para eles, o conceito de disseminação seletiva da informação. As palavras mais utilizadas pelos entrevistados para defini-lo foram: precisão, personalização, necessidade, interesse, economia de tempo, informação certa para o usuário certo.

Os entrevistados formados há mais tempo, demonstraram certa desilusão com o termo DSI. Essa desilusão pode ser explicada pelo decréscimo de publicações e debates sobre o assunto, a partir da metade dos anos de 1980. Indagados sobre qual seria a razão do desânimo com a DSI, eles responderam que, embora seja algo interessante e válido, as experiências que tiveram na utilização da DSI, não justificaram os esforços empregados.

Todos os entrevistados responderam que a DSI ainda possui utilidade para o serviço de referência. Indagados sobre a importância da disseminação seletiva com o crescimento da quantidade de informações na Internet, todos novamente afirmaram que, criar mecanismos que permitam difundir apenas informações de interesse dos usuários é algo a ser observado pelos serviços de referência. Das seis instituições visitadas, duas utilizam o serviço de DSI. Ao afirmarem que a disseminação seletiva de conteúdos da Internet é importante, os entrevistados foram questionados se a tecnologia RSS não seria uma forma de disseminação seletiva da informação. Quatro entrevistados afirmaram ver semelhança entre o conceito de DSI e a tecnologia RSS.

Indagados sobre a DSI ser um conceito ultrapassado todos os entrevistados responderam que não. $\mathrm{Na}$ realidade, os entrevistados afirmaram a utilidade do DSI, notadamente numa época em que a Internet difunde informações em quantidade impossível de ser absorvida pelos indivíduos e pelas próprias instituições de informação. 


\section{CONCLUSÕES}

Imaginar uma biblioteca, além de paredes, estantes, livros e pessoas, é um exercício que bibliotecários são convidados a fazer diariamente. Antes o papiro, até pouco tempo atrás o papel, agora o digital. Tais suportes mudaram a forma das bibliotecas existirem e desempenharem suas atividades. Há algum tempo os meios eletrônicos de comunicação e as representações da informação invadiram a vida das pessoas, consequentemente, sua realidade.

As bibliotecas digitais passam a ser discutidas, construídas e criticadas. Com elas surgem novos serviços, produtos e meios de interação com o usuário; é a Internet diminuindo distâncias, barreiras linguísticas e o tempo. Um desses meios de interação são os sítios das bibliotecas, portais interativos 24 horas por dia disponíveis para serem consultados pelos usuários.

Foi possível identificar que além de verificar a aplicabilidade da tecnologia RSS e da DSI nas bibliotecas, os sítios das bibliotecas são o grande ponto a ser estudado. Os setores de referência das bibliotecas visitadas ainda não conseguiram encontrar um equilíbrio entre os serviços de informação disponíveis fisicamente em cada unidade e os disponíveis em seus sítios. Sobre a aplicação da tecnologia RSS verificou-se pouco conhecimento dos profissionais a respeito, embora ela venha sendo empregada já há algum tempo em bibliotecas, principalmente, estrangeiras. O uso dessa tecnologia passa necessariamente pela utilização maior do sítio, porém como o uso ainda é tímido por parte dessas bibliotecas, era de se esperar certo desconhecimento.

Já sobre a disseminação seletiva de informação (DSI) foi possível constatar que o termo ainda é presente na vida dos profissionais, embora apenas duas bibliotecas a utilizem. Verificou-se que a não utilização da DSI não representa um desmerecimento do serviço, já que todos os entrevistados responderam ser importante a disseminação seletiva de conteúdos. Parece que a não utilização decorre da falta de tempo dos profissionais para planejar o serviço.

Ao se fazer uma análise entre os conceitos difundidos por Peter Luhn, por meio da DSI e os utilizados para a criação da tecnologia RSS, chega-se à conclusão que há proximidades entre os dois conceitos com pequenas diferenças. Ambos centram-se na difusão de conteúdos de acordo com a necessidade do indivíduo, a diferença consiste exatamente na forma como se constrói o perfil do indivíduo e o meio que são difundidas as informações. 
Na DSI a construção do perfil é um processo no qual a biblioteca atua na identificação das áreas de interesse do usuário, ou seja, esse perfil é construído antes da criação do serviço e é estático. Já na tecnologia RSS o perfil é criado pelo próprio indivíduo, que define suas próprias regras e temas de direito. O serviço existe antes mesmo da inscrição do usuário nos feeds, fazendo com que esse perfil seja dinâmico. Já a tecnologia RSS exige o ambiente da Internet para sua utilização, já que as fontes são exatamente as novas publicações nos sítios e páginas da Internet.

Nas bibliotecas os serviços eletrônicos já são realidade e presume-se que sejam amplamente utilizados no futuro. A novidade é o que movimenta a informação, essa mesma novidade é que deve incentivar os profissionais e as bibliotecas a repensarem suas atividades, seja por meio de cursos ou canais de comunicação formais e informais. A renovação de conteúdos é um elemento importante para a criação de novos produtos e serviços de informação.

\section{REFERÊNCIAS}

ALECRIM, Emerson. O que é RSS?, 2005. Disponível em: < http://www.infowester.com/rss. php>. Acesso em: 22 dez. 2010.

ALMEIDA, Robson Lopes de. Disseminação seletiva de conteúdos na web: a tecnologia RSS como proposta para a comunicação científica. 2008. 192 f. Dissertação (Mestrado) Universidade de Brasília, Brasília, 2008.

ANDERSON, Byron. Keeping Up: SDI to RSS. Behavioral Social Sciences Librarian, v. 24, n. 2, p. 113-117, 2006.

BADMAN, Derik A.; HARTMAN, Lianne. Developing current awareness services: virtual reading and online routling. College \& Research Library News, v. 69, n. 11, p. 670-672, 2008.

BAX, M. P.; ALVARENGA, Lídia; PARREIRAS, Fernando Silva; BRANDÂO, Wladimir Cardoso. Sistema automático de disseminação seletiva de informação. In: IFLA MANAGEMENT AND MARKETING, 2004, São Paulo. Anais eletrônicos... São Paulo: USP, 2004. Disponível em: <http://www.fernando.parreiras.nom.br/publicacoes/dsi_ifla.pdf $>$. Acesso em: 22 dez. 2010 
BORDA, João Carlos da Silva. Disseminação seletiva de informações: revisão bibliográfica e projeto para a Companhia Vale do Rio Doce. Revista de Biblioteconomia de Brasília; v. 1, n. 2, p. 181-191, jul./dez. 1973.

CARVALHO, Fernanda Cordeiro de. Educação e estudos de usuários em bibliotecas universitárias brasileiras: abordagem centrada nas competências em informação: Brasília, 145 f. Dissertação (Mestrado) - Universidade de Brasília, Departamento de Ciência da Informação e Documentação, 2008.

CERVO, Amado Luiz; BERVIAN, Pedro Alcino; SILVA, Roberto da. Metodologia científica. 6. ed. São Paulo: Pearson Prentice Hall, 2007. 162 p.

CHASTINET, Yone S; FONSECA, Ana Flávia M. da; LOBO, Paulo R. A.; ROBREDO, Jaime. Análise da expansão do serviço de bibliografias personalizadas em agricultura (BIP/AGRI): um serviço brasileiro de disseminação seletiva. Revista de Biblioteconomia de Brasília, v. 6, n. 2, p. 216-229, jul./dez. 1978.

CUNHA, Murilo Bastos da; CAVALCANTI, Cordélia R. de Oliveira. Dicionário de biblioteconomia e arquivologia. Brasília: Briquet de Lemos, 2008. 451 p. . Desafios na construção de uma biblioteca digital. Ciência da Informação, v. 28, n. 3, p. 257-268, $\quad$ set./dez. $1999 . \quad$ Disponível em: $<$ http://www.scielo.br/pdf/ci/v28n3/v28n3a3.pdf >. Acesso em: 10 jan. 2011.

DEFOURNY, Vincent. Apresentação. In: TARAPANOFF, Kira (Org.). Inteligência, informação e conhecimento. Brasília: IBICT, UNESCO, 2006. p. 7-8.

DIAS, Maria Matilde Kronka; PIRES, Daniela. Usos e usuários da informação. São Carlos: EdUFSCAR, 2004. 48 p.

FERRAZ, Terezine Arantes; FIGUEIREDO, Regina Célia. O serviço de "disseminação seletiva de informação executado na divisão de informação e documentação científicas do Instituto de Energia Atômica de São Paulo. Revista de Biblioteconomia de Brasília, v. 6, n. 2, jul./dez. 1978.

FONSECA, Edson Nery da. Ser ou não ser bibliotecário e outros manifestos contra a rotina. Brasília: Associação dos Bibliotecários do Distrito Federal, 1988. 260 p. 
FRÖEHLICH, T. J. The foundations of information science in social epistemology. In: ANNUAL HAWAII INTERNATIONAL CONFERENCE ON SYSTEM SCIENCES, 21. 1989. Proceedings. Washington, D.C.: IEE Computer Science Press, 1989. p. 306-315.

HENSLEY, C. B. Selective dissemination of information (SDI): state of the art in May, 1963. ACM, p. 257-262, 1963.

HJÖRLAND, B. Fundamentals of knowledge organization: trends in knowledge organization research. Knowledge Organization, v. 30, n. 2, p. 87-111. 2003.

KURAMOTO, Hélio. Acesso livre à informação científica: novos desafios. Linc em revista, v. 4 , n. 2 , p. $155-158$, set. 2008.

LANCASTER, F. W. Indexação e resumos: teoria e prática. 2. ed. ver. atual. Brasília: Briquet de Lemos, 2004. 452 p.

LEVINE, Alan. Pssss... have you heard about RSS?, 2003. Disponível em:

$<$ http://www.mcli.dist. maricopa.edu/forum/fall03/rss.html $>$. Acesso em: 12 jan. 2011.

LIMA, Maísa Pieroni de; CARVALHO, Maria Carmen Romcy de; OLIVEIRA, Maria das Graças C. de; CASTRO, Virgínia Gouvêa de. A disseminação da informação de maneira seletiva e eficaz no SERPRO. In: SANTOS, A. R. et al. Gestão do conhecimento: uma experiência para o sucesso empresarial. Curitiba: Champagnat, 2001. p. 195-232.

LUCAS, Elaine R. de Oliveira; SOUZA, Nicole Amboni de. Disseminação seletiva da informação em bibliotecas universitárias sobre o prisma do customer relationship management. Informação e Informação, v. 12, n. 1, jan./jun. 2007. Disponível em: $<$ http://www.uel.br/revistas/uel/index.php/informacao/article/viewFile/1745/1494>. Acesso em: 22 jan. 2011.

LUHN, Hans Peter. A bussines intelligence system. IBM Journal of Research and Development, v. 2 n. 4, p. 314-319, October 1958.

LUHN, Hans Peter. Selective dissemination of new scientific information with the AID of electronic processing equipment. American Documentation, v. 12, p. 131-138, 1961.

MACMANUS, Richard. RSS Reader Market in Disarray, Continues to Decline, 2009. Disponível $<$ http://www.readwriteweb.com/archives/rss_reader_market_in_disarray.p hp>. Acesso em: 10 jan. 2011.

MANGUEL, Alberto. A biblioteca à noite. São Paulo: Companhia das Letras, 2006. 301 p. 
MARCONDES, Carlos Henrique; MENDONÇA, Marília A.; CARVALHO, Suzana M. Serviços web em bibliotecas universitárias brasileiras. Perspectivas em Ciência da Informação, v. 11, n. 2, p. 174-186, maio/ago. 2006.

NOCETTI, Milton A. Avaliação dos pacotes bibliográficos do serviço automatizado de disseminação seletiva da informação da Empresa Brasileira de Pesquisa Agropecuária: SDI/EMBRAPA. Revista de Biblioteconomia de Brasília; v. 6, n. 2, p. 247-255, jul./dez. $1978 b$.

NOCETTI, Milton A. SDI Embrapa: o serviço de disseminação seletiva da informação do sistema de informação técnico-científica da Embrapa. Revista de Biblioteconomia de Brasília; v. 6, n. 2, p. 230-246, jul./dez. 1978a.

RAULINO, P. C. Disseminação seletiva da informação no Congresso Nacional. Revista de Biblioteconomia de Brasília, v. 1, n. 2, p. 169-179, jul./dez. 1973.

ROBREDO, Jaime. Redes de informação e de gestão do conhecimento: modelagem e estrutura de informações. In: TARAPANOFF, Kira. Inteligência, informação e conhecimento em corporações. Brasília: IBICT, UNESCO, 2006. p. 303-338.

ROCHA, Francisco das Chagas; BEZERRA, Porto. Um mecanismo de notificação para usuários de bibliotecas digitais. Revista F@pciência, v. 6, n. 11, p. 87-94, 2010. Disponível em: <http://www.fap.com.br/fapciencia/006/edicao_2010/011.pdf $>$. Acesso em: 22 fev. 2011.

ROWLEY, Jennifer. A biblioteca eletrônica. Brasília: Briquet de Lemos, 2002. 399 p.

SARDENBERG, Ronaldo Mota. Apresentação. In: TAKAHASHI, Tadao (Org.). Sociedade da informação no Brasil: livro verde. Brasília: Ministério da Ciência e Tecnologia, 2000. $195 \mathrm{p}$.

SINGH, Sukhdev. RSS and its use in libraries. 2008. 127 slides, color. Disponível em: $<$ http://www.slideshare.net/sukhi/rss-and-its-use-in-libraries $>$. Acesso em: 22 jan. 2011.

SOUTO, Leonardo Fernandes. Mediação em serviços de disseminação seletiva de informações no ambiente de bibliotecas digitais federadas. 2008. 238 f. Tese (Doutorado) - Universidade de São Paulo, São Paulo, 2008. Disponível em: $<$ http://www.dominiopublico.gov.br/pesquisa/DetalheObraForm.do?select_action=\&co_obra $=110077>$. Acesso em: 12 jan. 2011 . 
TAKAHASHI, Tadao. A sociedade da informação. In: (Org.). Sociedade da informação no Brasil: livro verde. Brasília: Ministério da Ciência e Tecnologia, 2000. 195 p. TARAPANOFF, Kira. Informação, conhecimento e inteligência em corporações: relações e complementaridade. In: TARAPANOFF, Kira. Inteligência, informação e conhecimento em corporações. Brasília: IBICT, UNESCO, 2006. p. 19-36.

WILSON, Thomas D. Recent trends in users studies: action research and qualitative methods. Information Research, v. 5, n. 3, 2000. Disponível em: <http://informationr .net/ir/5-3/paper76.html>. Acesso em: 22 dez. 2010.

WUSTEMAN, Judith. RSS: the latest feed. Library Hi Tech, v. 22, n. 4, p. 404-413, 2004. 